\title{
Successful Transition to Adulthood: Do We Really Need to Teach Shopping, Sex and Social Skills?
}

\author{
Jane Finn1*, Vicki-Lynn Holmes ${ }^{2}$, and Elizabeth Horton ${ }^{1}$ \\ ${ }^{1}$ Division of Education and Special Education, Hope College, Holland, Michigan, United States \\ ${ }^{2}$ Division of Mathematics, Hope College, Holland, Michigan, United States \\ Email: finn@hope.edu
}

\begin{abstract}
Living independently is an envisioned post-school outcome for many individuals with disabilities. One roadblock for this outcome for individuals with intellectual disabilities is insufficient self-determination or autonomy skills. The purpose of this study was to determine which autonomy skill (i.e., Self \& Family Care, Self-management, Recreation, and Social \& Vocational skills) was the greatest predictor of successful independent living as measured on the Transition Planning Inventory2 (Clark \& Patton, 2006) with individuals with moderate intellectual disabilities. Results show that Self \& Family Care is the greatest predictor of successful independent living. Based on these findings, families and schools should address Self \& Family Care curriculum and best practices in order to enable individuals with moderate intellectual disabilities to develop skills necessary for independent living.
\end{abstract}

Keywords: Intellectual disabilities, independent living skills, post-school transition.

\section{Introduction}

Independent living is a vital aspect of becoming an adult in today's society and a shared goal of both individuals with and without disabilities. However, several studies indicate that a great number of individuals with disabilities have not achieved post-school success related to residential independence (Cooper, O'Hara, \& Zovistoski, 2011; O'Hara, Cooper, Zovistoski \& Buttrick, 2007; Woolf, Woolf \& Oakland, 2010). Many of these individuals live with assistance from family members or in a type of supervised group home with a continual house supervisor (Association of Regional Center Agencies, 2003; Prouty, Smith, \& Lakin, 2001).

There are many challenges to residential independence for adults with intellectual disabilities including limited affordable housing options (Cooper et. at, 2011; Karaim, 2012; O'Hara et. at, 2007). Other challenges are personal in nature and are required in everyday life. These challenges include taking responsibilities for daily tasks such as personal hygiene, cleaning the house, participating in leisure or community activities, communicating effectively and advocating for oneself (Cooper, et al., 2011; O'Hara, et al., 2007; Woolf, Woolf \& Oakland, 2010).

The majority of these everyday life skills require self-determination, and one wonders if selfdetermination could be a successful indicator of independent living skills for individuals with intellectual disabilities. Historically, self-determination for individuals with disabilities is defined as the ability to control one's life (Nirje, 1972; Williams, 1989). Using this definition, self-determination and empowerment were used interchangeably (Weymeyer, 1995). Our explanation of self-determination is based on Wehmeyer's functional theory of self-determination (Wehymer, Abery, \& Stancliffe, 2003) that is based on the notion that individuals who have the ability to use self-determination actively control their behavior (Wehmeyer \& Abery, 2013). Wehmeyer (2005) notes that self-determination involves purposeful actions that result in specific consequences, and describes individuals capable of practicing self-determination as causal agents (Wehmeyer, 1992, Wehmeyer, 2005, Wehmeyer \& Abery 2013). In other words, individuals who practice self-determination purposefully act in ways to achieve specific goals and outcomes. Wehmeyer's functional theory of self-determination defines four fundamental factors: "(1) the person acts autonomously; (2) the behavior is self-regulated; (3) the person initiates and 
responds to the event(s) in a psychologically empowered manner; and (4) the person acts in a selfrealizing manner" (Wehmeyer \& Abery, 2013, p. 399).

In this present study, we are focusing on autonomous functioning in order to investigate the independent living skills of individuals with moderate intellectual disabilities. To understand this in depth, it is important to understand the theory of autonomous functioning. Four essential characteristics of autonomous functioning were operationalized by research completed by Sigafoos, Feinstein, Damond, \& Reiss (1988) and include behaviors that relate to self and family care, selfmanagement, recreation, and social or vocational activity (Wehmeyer, 1995). The characteristics of autonomy relate to daily living skills and activities (Sigafoos, et al, 1988; Wehmeyer, 1995; Sheppard and Unsworth, 2011):

1. Self and family care includes activities such as domestic chores, shopping, cooking and meal planning.

2. Self-management includes an individual's ability to navigate the community environment such as budgeting, using public transportation, and accessing resources.

3. Recreation includes activities that relate to leisure and the individual's ability to make choices regarding personal preference.

4. Social and vocational includes relevant activities as well as the individual's ability to determine preference and involvement.

\section{Purpose}

The purpose of this research is to examine the relationship between autonomy and independent living skills. Autonomous functioning is an essential characteristic of self-determination and it is important to assess and more fully understand autonomous functioning in individuals with intellectual and developmental disabilities in residential programs (Sheppard and Lunsworth, 2011). Research indicates (Farlow \& Snell, 2006, Sheppard \& Unsworth, 2011) that self-care activities are important predictors of vocational success, and research has addressed autonomy in individuals with intellectual and developmental disabilities in residential settings. However, there is a need for future in-depth research on the autonomous functioning of young adults with intellectual disabilities. This study addresses the following research question: Which of the four autonomy characteristics has the greatest impact on independent living skills for young adults with moderate intellectual disabilities?

\section{Method}

This study examined the independent living skills of individuals with moderate intellectual disabilities who lived semi-independently in a university residence hall. Human subjects approval was obtained prior to the research, and each participant gave consent to participate in the study.

\subsection{Participants and Setting}

For this study, we conducted research with individuals with intellectual disabilities who lived side-byside with individuals without disabilities in an on-campus residential hall. After exploring other types of housing at colleges and universities, it was noted that this was the only type of dorm that was set aside to accommodate only graduate students and individuals with disabilities. This unique residence hall is located in a small university in the Midwest region of the United States. The hall consisted of four suites and each suite contained three rooms for nondisabled individuals and one room for an individual with a moderate intellectual disability. The roommates shared a bathroom and other common areas such as a kitchen, laundry facility, and TV room. The nondisabled roommates were full-time graduate students whereas the individuals with ID were not students but required to have a job (i.e., paid or unpaid) and be able to attend to personal needs (e.g., cook simple meals and manage personal hygiene needs). Each roommate with ID had a "mentor" roommate with whom they developed a close relationship.

For this research, purposive sampling was used to select participants who had primary knowledge of the individuals' with intellectual disabilities independent living skills (Fraenkel, Walden, 1993). The selected participants were the individuals with intellectual disabilities, the non-disabled mentor 
roommates, and the parents of these roommates with intellectual disabilities. This is the only residential hall of its kind - meaning the entire hall has suites with individuals with and without disabilities living together in a graduate school. It should be noted that only six individuals with intellectual disabilities live in this unique residence hall. While we wish we could have studied more participants, were able to recruit one hundred percent of the selected sample living in this hall. Each roommate with intellectual disabilities resided at the residence hall for a minimum of three years, which helped more precisely determine the effect of living at the residence. The demographic breakdown is noted in Table 1.

\subsection{Procedures}

A packet consisting of a formal invitation to participate in the study, a consent form, and a selfaddressed, stamped return envelope was mailed to the all roommates with ID, six roommates without disabilities and a parent or guardian of each roommate with ID. The individuals with ID were their own guardians and able to indicate consent to participate in the study; but for full disclosure, the guardians were also notified and consent was given in accordance with approval from Human Subject Review. For those who did not initially respond, the packet was mailed out once again. These mailings resulted in a 100 percent response rate from the six roommates with ID, six roommates without a disability, and six parents.

Table 1. Population, n, Percentage Participating, Age Range and Gender of Participants

\begin{tabular}{|c|c|c|c|c|}
\hline Population & $n$ & Percentage Participating & Age Range & Gender \\
\hline $\begin{array}{l}\text { Roommates } \\
\text { Nondisabled }\end{array}$ & 6 & $100 \%$ & $21-26$ & $\begin{array}{l}4 \text { males / } \\
2 \text { females }\end{array}$ \\
\hline Disabled & 6 & $100 \%$ & $23-30$ & $\begin{array}{l}4 \text { males/ } \\
2 \text { females }\end{array}$ \\
\hline Parent & 6 & $100 \%$ & NA & $\begin{array}{l}1 \text { male / } \\
5 \text { females }\end{array}$ \\
\hline
\end{tabular}

Upon receiving consent, the Transition Planning Inventory-2 (TPI) was mailed to each parent/guardian and non-disabled mentor roommate. Upon completion of the survey, the participants mailed the completed TPI back to the researchers in a self-addressed stamped envelope. All of the individuals who signed the consent form returned a completed TPI $(\mathrm{N}=18)$. Research assistants orally administered the TPI to the roommates with ID $(\mathrm{n}=6)$. Three research assistants received over a two hours in training from the principal investigators on how to orally administer the TPI to individuals with ID. The three research assistants were present as the TPI was administered to each roommate with ID. One research assistant administered the TPI while the other two research assistants ensured fidelity of implementation. In addition, the three research assistants were required to come to consensus on scores; therefore, the inter-rater reliability was computed as 100 percent. Anonymity was preserved as all participants were asked not to place their names on the survey; an identifying number was placed on the surveys, thus eliminating any potential risk or repercussions for the participants.

While there is information regarding the six individuals with intellectual disabilities, the complete data set represents the responses of 18 persons comprised of roommates with intellectual disabilities, his/her mentor roommate and his/her parent. To mitigate the bias of small sample size and increase reliability of our generalized results, we conducted a re-sampling bootstrap method of analysis. This estimation method allows statistical analysis of small sample sizes, as it repeats 1000 times our study parameters using random samples of our original participants (Chernick, 2008; Singh \& Xie, 2008; Scholz, 2007; Sheather, 2009). These bootstrapped results are recorded throughout the paper.

\subsection{Measures}

The researchers wanted to use a standardized instrument that assessed disabled individuals' current 
knowledge and skill performances associated with living as an independent adult. This assessment needed to also align with the federal law named the Individuals with Disabilities Education Improvement Act or IDEA (2004) concerning transition skills to post-secondary life. The TPI was chosen for this research since it is a standardized transition planning instrument commonly used in the special education and agency fields. The TPI is used to evaluate and determine the strengths of individuals with disabilities and also focuses on the areas of growth in relation to postsecondary transitions in accordance to IDEA (2004). In addition, the TPI meets the evidence-based research recommendations of No Child Left Behind Act (2001) renamed to Every Student Succeed Act (2015) and the mandate of IDEA (2004) for appropriate transition assessments (Clark \& Patton, 2006).

The number of items on each transition construct is in parentheses: Employment (five items), Further Education or Training (five items), Daily Living (six items), Leisure Activities (three items), Community Participation (six items), Health (six items), Self-determination (five items), Communication (four items), and Interpersonal Relationships (six items). The TPI questions were reclassified to correspond with Wehmeyer's definition of autonomy. The four skill constructs of autonomy include Social \& Vocational, Self \& Family Care, Life Management, and Recreation \& Leisure (see Table 2).

The TPI instrument contains three rater forms that are given to the individual with the disability, a parent, and one other observer (e.g., teacher, school personnel, roommate, etc.). The raters rank the individual with a disability in respect to transitional abilities on a Likert scale of zero to five, zero indicating "strongly disagree" and five indicating "strongly agree". The participants also have the option to respond with DK (i.e., "don't know") or NA (i.e., "not applicable"). For the purposes of analysis, we transposed the zero-five scale to a one-six scale. In this way, we avoided potentially dividing by zero.

Table 2. TPI Autonomy Focus Areas, Item Numbers, and n of Items

\begin{tabular}{lll}
\hline TPI autonomy area & Items & $\boldsymbol{n}$ \\
\hline Social \& Vocational & $1-10,37-46$ & 20 \\
Self \& Family & $11,14,26-31$ & 8 \\
Life Management & $12-13,15-16,20-25$ & 10 \\
Recreation \&Leisure & $17-19$ & 3 \\
Independent Living Construct & All items & 46 \\
\hline
\end{tabular}

An overall TPI score is the individual's composite transition score (i.e., maximum of 230 points) that was used to determine the overall TPI score or the Independent Living Construct. Transition scores are also provided for each of the four autonomy constructs. The rater scores of each construct were averaged to determine the four autonomous sub scores. The TPI's autonomous and overall reliability was confirmed $(\alpha=.816, .796$, respectively). Content validity was examined by relating the questions on the TPI to other transition assessments (e.g., Enderle-Severson Transition Rating Scale and Arc's Selfdetermination Scale).

\subsection{Data Analysis}

Descriptive statistics (e.g., means, standard deviations, percentages) were reported for each of the autonomous constructs, (i.e., characteristics). A regression analysis was run to determine the impact of each independent living construct. Because of the small sample size, a bootstrapped regression based upon 1000 samples was run using the following formula:

Independent Living $=$ Social \& Vocational + Self $\&$ Family Care + Life Manage + Recreation \& Leisure $+\mathrm{e}$

To compare magnitudes of each construct, effect sizes (standardized b and d) were reported (Cahan \& Eyal, 2011; Landis \& Koch, 1977). The partial correlation was squared to determine the percent of variance explained for each of the four autonomous characteristics. All assumptions (i.e., linearity, normality, and homoscedastic) were met. Because the regression results report if constructs are significant, but not if they are significantly different in comparison to each other, t-tests on the effect sizes were also used. Each effect size was compared to the norm. Finally, two reliability coefficients were 
computed, the intraclass correlation coefficients to determine magnitude of rater agreement and Cronbach's Alpha to determine item consistency among the four constructs of autonomy (Cohen, 1988; Cronk, 2012; LeBreton \& Senter, 2007). All assumptions were met (i.e., independence, normality, influential outliers, homogeneity of variance, multicollinearity).

\subsection{Results}

The purpose of this study was to determine the effects of autonomy on independent living skills in respect to the individuals with ID in our study. Specifically, using Wehmeyer's definition of autonomy, we investigated which autonomous characteristics had the most impact on independent living skills. Wehmeyer's four autonomous skill constructs are Social \& Vocational, Self \& Family Care, Life Management, and Recreation \& Leisure. To ascertain results, we surveyed the individuals with ID, the nondisabled roommates, and a parent/guardian of the individual with ID.

The intraclass correlation coefficient (ICC) was computed to determine the degree of consistency or agreement among the three scorers (individual with ID, roommate, and parent/guardian). Results show moderate agreement among the scorers $(\mathrm{ICC}=.53)$; hence, the results based upon their scores are reliable. Statistics supported reliability of our group of three raters (i.e., average measures of the intraclass correlation) and instrument reliability $(\alpha=.82)$.

Descriptive results indicate that our individuals with moderate intellectual disabilities demonstrated a strong sense of autonomy, averaging 4.5 on a 6 point Likert scale (75\%). Additionally, the four characteristics of autonomy explain $74 \%$ of Independent Living (Adj R2 =.74). These individuals with ID scored highest in Self \& Family Care (81\%) and Recreation \& Leisure $(80 \%, \mathrm{M}=4.86, \mathrm{SD}=.76$ and $\mathrm{M}=4.82, \mathrm{SD}=.89$, respectively); and lowest in Life Management $(63 \%, \mathrm{M}=3.79, \mathrm{SD}=1.07)$. See the descriptive autonomy statistics in a six point Likert Scale in Table 3.

Table 3: Autonomy Area, Mean, SD of PTI items (n=1010)

\begin{tabular}{llr}
\hline Autonomy Area & $\boldsymbol{M}$ & $\boldsymbol{S D}$ \\
\hline Independent Living Score & 138.23 & 24.87 \\
Social \& Vocational & 4.59 & .72 \\
Self \& Family & 4.86 & .76 \\
Life Management & 3.79 & 1.07 \\
Recreation\& Leisure & 4.82 & .89 \\
\hline
\end{tabular}

A bootstrapped linear regression was calculated to predict the effect of the four autonomous characteristics on independent life skills. A significant regression equation was found $(\mathrm{F}(4,1005)=$ 735.791, p < .001), with an adjusted R2 of .744. The resulting regression equation is: Independent Living $=10.55$ (Self \& Family Care) + 6.54 (Life Management) + 9.72 (Social \& Vocational) +5.77 (Recreation \& Leisure) - 10.181. This regression line describes how the autonomous characteristics affect Independent Living; it shows how Independent Living changes as our autonomous characteristics change. On average, as Independent Living increases (per standard deviation), the autonomy increases about a fourth of a standard deviation. Within the characteristics, as Independent Living increases (per standard deviation), Self \& Management skills have the largest impact, increasing about a third of a standard deviation $(\beta=.324)$; while Recreation \& Leisure will have the least impact, increasing about a fifth of a standard deviation $((\beta=.205)$ (see Table 4 and Figure 1$)$.

Each of the four characteristics of autonomy was a significant predictor of Independent Living. As such, d was (pr2) to determine the percent of variance explained (see Table 4 and Figure 1 above). In other words, we determined how each characteristic of autonomy uniquely impacted independent living and estimated the percent that each of the autonomy characteristics, individually, impact or explain the Independent Living score. Both of these statistics help to understand the unique impact of Self \& Family Care, Life Management, Social \& Vocational, and Recreation \& Leisure on Independent Living; they do not include interaction effects among the four characteristics.

By far, Self \& Family Care explains $26 \%$ of Independent Living, contributing a moderate effect on independent living skills $(\mathrm{d}=.68$, corresponding pr2 $=.26$ ). Life Management and Social \&Vocational 
each has a moderate effect, explaining approximately $10 \%$ of Independent Living $(\mathrm{d}=.58$ and .59 , respectively, corresponding pr2 $=.09$ and .10 , respectively). Recreation \& Leisure has a small effect on Independent living, explaining approximately $5 \%$ of the variance $(\mathrm{d}=.42$, corresponding $\mathrm{pr} 2=.05)$. Since the overall effect of the four characteristics was $74 \%$, the remaining $24 \%$ can be attributed to the interactive effects of these autonomous characteristics.

Table 4: TPI Autonomy Characteristics Regression Coefficient

\begin{tabular}{|c|c|c|c|c|c|c|c|}
\hline & B & $O$ & $B$ & $t$ & Pr2 & $p$ & Cohen's $d$ \\
\hline Constant & -10.18 & 3.55 & -- & -2.87 & -- & .004 & -- \\
\hline Social \& Vocational & 9.72 & 0.90 & 0.280 & 10.78 & .103 & .000 & 0.5835 \\
\hline Self \& Family & 10.55 & 0.56 & 0.324 & 18.90 & .262 & .000 & 0.6851 \\
\hline Life Management & 6.54 & 0.67 & 0.282 & 9.72 & 0.86 & .000 & 0.588 \\
\hline Recreation \& Leisure & 5.77 & 0.81 & 0.205 & 7.12 & 0.48 & .000 & 0.419 \\
\hline
\end{tabular}

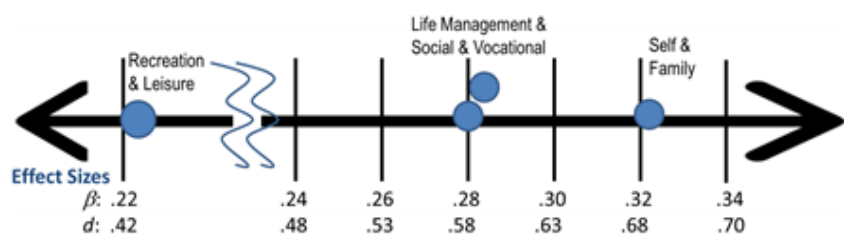

Figure 1: TPI Autonomy Effect Impact Scale

\section{Discussion}

Wehmeyer's definition of autonomy explains $74 \%$ of independent living skills as rated by the TPI-2 (Clark \& Patton, 2006). This assessment correlates with other quality of life scales such as the Personal Outcomes Scale developed by Claes, Van Hove, Van Loon, Vandevelde and Schalock (2009). The characteristics of autonomy, as defined by Wehmeyer, are: (1) recreation and leisure, (2) life management, (3) social and vocational and (4) self and family.

While all four factors were significant, the strongest predictor of independent living success was "self and family." This finding concurs with research from Felce, Perry and Kerr (2011) that shows that higher household participation is an important part of learning and success in an independent living setting. An important facet of self and family care is knowledge of reproduction and sexual behavior, and it is critical that individuals with intellectual disabilities are taught how to manage this aspect of life. However, research shows that family members, teachers and other agency personnel often lack confidence in addressing these sexual issues with young adults with disabilities (Evans, McGuire, Healty \& Carley, 2009; Pownall, Jahoda, Mstings, \& Kerr, 2011).

Sex education is especially important since people with intellectual disabilities can be at greater risk for sexual abuse (Horner-Johnson \& Drum, 2006). Additionally, another aspect of "self and family" that should be taught is physical health. Research has shown that exercise and good physical health improve psychological well-being (Hayes \& Ross, 1986), and advocates for individuals with intellectual disabilities need to focus on this area.

Interestingly, the impact of "social and vocational factors" and "life management" on autonomy were equivalent. Often times, these vocational and social skills (e.g., knowing how to get a job, how to get into a vocational school, and how to listen, speak, read and write) are taught in the high school setting as part of the transition process. Limited research addresses best practice for teaching vocational skills 
that lead to permanent employment. Speat and Conroy (2015) discussed, in a fifteen-year longitudinal study, the overall decline of vocational and prevocational activities as well as the decline of the employment of individuals with intellectual disabilities. Further, Ticha, Hewitt, Nord, and Larson (2013) note that the number of individuals with intellectual disabilities who received employment services increased from 287,860 to 570,406 between 1988 and 2011. However, the researchers point out that little growth in these services occurred between 2011 and 2013. National data indicates that roughly a quarter of individuals with developmental disabilities who receive employment services find employment (Ticha, Hewitt, Nord, \& Larson, 2013). Further research needs to address how to prepare individuals with intellectual disabilities to be strong job candidates and to seek and retain employment.

"Life management" requires an individual to be knowledgeable of how to locate a place to live, setup an apartment or house, manage finances, know how to use transportation, and understand basic legal rights. Based on the experiences of the participants in this study, family and friends were eager to assist the individuals with intellectual disabilities in these areas, which may actually inhibit the development of this skillset. Our findings suggest that "life management" is a significant predictor of autonomy and should be fully developed.

Finally, the least impactful characteristic was "recreation and leisure." We want to note that this is still a good predictor of autonomy. Research confirms that individuals with disabilities that have better developed recreation and leisure skills rank higher in autonomy. Further research needs to address evidence-based methods for teaching such skills to individuals with intellectual disabilities (Test, Mazzotti, Mustian, Fowler, Kortering \& Koher, 2009; Wehman, 2006). Although many educators may enjoy teaching recreation and leisure skills, pragmatically speaking, more instructional time should be devoted to teaching "self and family," "life management," and "social and vocational" skills as they are greater predictors of autonomy.

Another interesting finding of this research was that the individuals with moderate intellectual disabilities were reliable self-reporters of their transition skills and their scores were similar with the scores of the other reporters (parents, and nondisabled roommates without disabilities). This finding differs from Janssen, Schuenge and Stolk's (2004) research that showed discrepancies in the ratings between caregivers and individuals with intellectual disabilities concerning the quality of life indicators. Very little is known about the validity of information collected via proxy reporters; however, our results show that the proxy reporters were just as accurate as those individuals with disabilities. In addition, our results may be predicated on the fact that it was ensured that all persons understood the TPI questions. This confirms research suggesting that when gathering information from individuals with intellectual disabilities, educators and researchers examine the subject's ability to communicate and comprehend the questions being posed (Emerson, Felce, \& Stancliffe, 2013). There is a great need for further research in this area, and Fujiura (2012) notes that few researchers have made the effort to develop strategies and interventions for teaching individuals with intellectual disabilities how to comprehend and respond to questions regarding their future. Therefore, our research shows that the young adults with moderate intellectual disabilities know themselves and these self-scores should be considered accurate and reliable.

\section{$5 \quad$ Limitations}

This current study provides meaningful information regarding predictors of autonomy for individuals with intellectual disabilities. Although bootstrapping mitigated the limitations of our small sample size, it would be remiss not to mention the caution of generalizability. All of the participants were adults with intellectual disabilities and the sample size limits the ability to generalize to a broader population of individuals at varying ages and with varying types of disabilities.

\section{Conclusions}

The purpose of this current study was to determine which autonomy characteristics were the greatest predictors of independent living as measured on the TPI-2 (Clark \& Patton, 2006). The four characteristic of autonomy are: self \& family care, self-management, recreation, and social and vocational. All of the autonomy characteristics were significant predictors; however, results indicated 
that self and family care is the greatest predictor of autonomy while recreation and leisure is the least significant. Based on this finding, future research should address best practices related to each characteristic of autonomy especially self and family care in order to enable individuals with intellectual disabilities to develop much needed independent living skills. It is also interesting to note that there was moderate agreement among scorers on the TPI between the three scorers (i.e., roommate with a disability, nondisabled roommate, and parent). This suggests that individuals with moderate intellectual disabilities are reliable predictors of their own autonomy. More research should address the reliability of self-reports from individuals with disabilities.

\section{References}

1. Association of Regional Center Agencies. (2003). State of the state in developmental disabilities: 2002 study summers. Retrieved from http://arcanet.org/pdfs/StateOfState.pdf.

2. Cahan, S. \& Eyal G. (2011). First among others? Cohen's d vs. alternative standardized mean group difference measures. Practical Assessment, Research \& Evaluation, 16(10).

3. Chernick, M.R. (2008). Bootstrap methods: A guide for practitioners and researchers. Hoboken, NJ: WileyInterscience.

4. Clark, G., \& Patton, J. (2006). The Transition Planning Inventory: Administration and resource guide. Austin, TX: PRO-ED Inc.

5. Claes, C., Van Hove, G., Van Loon, J., Vandevelde, S., \& Schalock, R. (2010). Quality of life measurement in the field of intellectual disabilities: Eight principles for assessing quality of life-related personal outcomes. Social Indicators Research, 98(1), 61-72. doi:http://dx.doi.org.mutex.gmu.edu/10.1007/s11205-009-9517-7

6. Cohen, J. (1988). Statistical power analysis for the behavioral sciences (2nd ed.). Hillsdale, NJ: Lawrence Earlbaum Associates.

7. Cooper, E., O'Hara, A., \& Zovistoski, A., (2011). Priced out in 2010: The housing crisis for people with disabilities. Technical Assistance Collaboration. Retrieved from

https://www.aucd.org/docs/policy/PricedOut2010.pdf

8. Cronk, B.C. (2012). How to use SPSS statistics: A step-by step guide to analysis and interpretation. Los Angeles, CA: Pyrczak Publishing.

9. Emerson, E., Felce, F., \& Stancliffe, R. J. (2013). Issues concerning self-report data and population-based data sets involving people with intellectual disabilities. Intellectual and developmental disabilities, 51, 333-348. doi: 10.1352/1934-9556-51.5.333

10.Evans, D., McGuire, B., Healty, E., \& Carley, S. (2009). Sexuality and personal relationships for people with an intellectual disability. Part II: Staff and family carer perspectives. Journal of Intellectual Disabilities Research, 53, 913-921. doi: 10.1111/j.1365-2788.2009.01202.x

11.Farlow,L. J. \& Snell, M. J. (2006). Teaching Self Care Skills. In Snell, M. E., \& Brown, F. E. (Eds.), Instruction of Students with Severe Disabilities (pp. 89-110). New York: Pearson Publishing.

12.Felce, D., Perry, J., \& Kerr, M. (2011). A comparison of activity levels among adults with intellectual disability living in family homes and out-of-family placements. Journal of Applied Research in Intellectual Disabilities, 24, 421-426. doi: 10.1111/j.1468-3148.2010.00620.x

13.Fujirura, G. T. (2012). Self-reported health of people with intellectual disability. Journal of Intellectual Disability Research, 41, 126-143. doi: 10.1352/1934-9556-50.4.352.

14.Fraenkel, J. R., \& Wallen, N. E. (1993). How to design and evaluate research in education (2nd ed.). Boston, MA: McGraw Hill.

15.Karaim, R. (2012). People with mental retardation. Housing first: A special report. Retrieved from http://npr.org/news/specials/housingfirst/whoneeds/mentalretardation.html

16.Hayes, D., \& Ross, C. (1986). Body and mind: The effect of exercise, overweight, and physical health on psychological well-being. Journal of Health and Social Behavior, 27, 387-400.

17.Horner-Johnson, W., \& Drum, C. (2006). Prevalence of maltreatment of people with intellectual disabilities: A review of recently published research. Mental Retardation and Developmental Disabilities Research Reviews, 12, 57-69. doi:10.1002/mrdd.20097.

18.Individuals with Disabilities Education Improvement Act, 20 U. S. C. § 1400, et seq. (2004). 
19.Janssen, C., Schuengel, C., \& Stolk, J. (2004). Perspectives on quality of life of people with intellectual disabilities: The interpretation of discrepancies between clients and caregivers. Quality Life Resources, 14, 57-69. Doi: $10.1007 / \mathrm{s} 11136-004-1692-\mathrm{z}$

20.Landis J.R. \& Koch G. G. (1977). The measurement of observer agreement for categorical data. Biometrics, 33 , $159-74$.

21.LeBreton, J. M., \& Senter, J. L. (2007). Answers to 20 questions about inter-rater reliability and inter-rater agreement. Organizational Research Methods, 11, 815-852. doi: 10.1177/1094428106296642

22.Nirje, B. (1972). The right to self-determination. In Wolfensberger, W. (Ed.), Normalization: The principle of normalization (pp. 176-200). Toronto: National Institute on Mental Retardation.

23.No Child Left Behind (NCLB) Act of 2001, 20 U.S.C.A. $§ 6301$ et seq. (West 2003).

24.O'Hara, A., Cooper, E., Zovistoski, A., \& Buttrick, J. (2006). Priced out in 2010: The housing crisis for people with disabilities. Opening Doors, 30, 13-30.

25.Pownall, J. Jahoda, A, Mastings, R., \& Kerr, L. (2011). Sexual understanding and development of young people with intellectual disabilities. Mothers' perspectives of within-family context. American Journal on Intellectual and Developmental Disabilities, 116, 205-219. doi: http://dx.doi.org/10.1352/1944-7558 116.3.205

26.Prouty, R., Smith, A. \& Lakin, K. (2001). Residential services for persons with developmental disabilities: Status and trends through 2000. Minneapolis, MN: University of Minnesota, Research and Training Center of Community Living Institution on Community Integration. The College of Education and Human Development.

27.Scholz, F. (2007). The bootstrap small sample properties. University of Washington, Seattle. Retrieved from http://www.stat.washington.edu/fritz/Reports/bootstrap-report.pdf.

28.Sigafoos, A., Feinstein, C., Damond, M., \& Reiss, D. (1988). The measurement of behavioral autonomy in adolescence. The Autonomous Functioning Checklist. Adolescent Psychiatry, 15, 432-462.

29.Singh, K. \& Xie, M. (2008). Bootstrap: A statistical method. Rutgers University. Retrieved from http://stat.rutgers.edu/home/mxie/RCPapers/bootstrap.pdf

30.Sheather, S. J. (2009). A modern approach to regression with R. New York: Springer.

31.Sheppard, L., \& Unsworth, C. (2011). Developing skills in everyday activities and self-determination in adolescents with intellectual and developmental disabilities. Remedial and Special Education, 32(5), 395-405. doi: $10.1177 / 0741932510362223$

32.Spreat, S., \& Conroy, J. (2015). Longitudinal investigation of vocational engagement. Journal of Policy and Practice in Intellectual Disabilities, 12, 266-271. doi: 10.1111/jppi.12136

33.Test, D., Mazzotti, V., Mustian, A, Fowler, C., Kortering, L., \& Kohler, P. (2009). Evidence-based secondary transition predictors for improving postschool outcomes for students with disabilities. Career Development for Exceptional Individuals, 32(3), 160-181. Doi:10.1177/08885728809346960

34.Ticha, R., Hewitt, A., Nord, D., \& Larson, S. (2013). System and individual outcomes and their predictors in services and support for people with IDD. Intellectual and Developmental Disabilities, 51(5), 298-315. doi: 10.1352/1934-9556-51.5.298

35.U.S. Department of Education. (2015). Every student succeeds act summary. Retrieved from http://www.ed.gov/ESSA

36.Wehman, P. (2006) Life beyond the classroom: Transition strategies for young people with disabilities. (4th Ed.). Baltimore: Paul H. Brookes.

37.Wehmeyer, M. L. (1992). Self-determination and the education of students with mental retardation. Education and Training in Mental Retardation, 27, 302-314.

38.Wehmeyer, M. L. (1995). The ARC Self Determination Scale: Procedural Guidelines. The ARC of the United States. Retrieved from http://www.thearc.org/document.doc?id=3671

39.Wehmeyer, M. L., \& Abery, B. H. (2013). Self-determination and choice. Intellectual and Developmental Disabilities, 51, (5), 399-411. doi: 10.1352/1934-9556-51.5.399

40.Wehmeyer, M., Abery, B., \& Stancliffe, L. (2003). Theory in self-determination: Foundations for educational practice. Springfield, IL: Charles C. Thomas Publishers.

41.Williams, R. R. (1989). Creating a new world of opportunity: Expanding choice and self-determination in lives of Americans with severe disability by 1992 and beyond. In R. Perske (Ed.), Proceedings from the National Conference on Self- Determination (pp. 16-17). Minneapolis: Institute on Community Integration.

42.Woolf, S., Woolf, C., \& Oakland, T. (2010). Adaptive behavior among adults with intellectual disabilities and its relationship to community independence. Intellectual and Developmental Disabilities, 48, 209-215. doi: 10.1352/1944-7558-48.3.209. 